\section{Chiari type I malformation, syncope, headache, hypoglycemia and hepatic steatosis in an 8-year old girl: a causal association?}

\author{
Luigi Tarani, Francesca Del Balzo, \\ Francesco Costantino, Enrico Properzi, \\ Patrizia D'Eufemia, Natascia Liberati, \\ Alberto Spalice \\ Chair of Paediatrics, Department of \\ Paediatrics, University “La Sapienza”, \\ Rome, Italy
}

\begin{abstract}
Chiari type I malformation (CMI) is a congenital hindbrain anomaly characterized by downward displacement of the cerebellar tonsils through the foramen magnum. Chiari type I malformation often presents with a complex clinical picture and can be sporadic or linked to a variety of genetic conditions. We report on a girl in whom Chiari type I malformation was associated with hypoglycemia, headache, vertigo, syncope and hepatic steatosis. We hypothesize that these symptoms are primarily a consequence of Chiari type I malformation.
\end{abstract}

\section{Introduction}

Chiari type I malformation (CM-I) comprises a continuum of pathological hindbrain malformations, clinically defined as an inferior displacement of the cerebellar tonsils below the foramen magnum, and the condition is thought to be caused by reduced posterior fossa volume. ${ }^{1} \mathrm{CM}-\mathrm{I}$ is the most common form of Chiari and the phenotype continues to be refined as more research is conducted on the disorder. ${ }^{1,2}$ The incidence of Chiari I is unknown, but the prevalence may be as high as one in $1,2800^{3,4}$

Chiari I is frequently associated with a number of other abnormalities. A prospective study of 265 patients with CMI reported headaches (98\%), dizziness (84\%), disequilibrium (46\%), neck pain (67\%), sleep difficulty (72\%), weakness in the upper (69\%) or lower (52\%) extremities, numbness or tingling in the upper (62\%) or lower extremities (43\%), difficulty in swallowing (54\%), shortness of breath (57\%), nausea (58\%), blurred vision (57\%), depression (47\%), tinnitus (56\%), memory problems (45\%), slurred speech (28\%), raspy or hoarse voice (41\%), cardiac abnormalities (39\%), and facial numbness (32\%). ${ }^{5}$ These constellations of symptoms are not individually unique to
Chiari and make diagnosis difficult, particularly when $95 \%$ of patients report more than five symptoms. ${ }^{6-13}$ They are highly variable and occur in multiple combinations, reflecting dysfunction of the cerebellum, brainstem, or spinal cord (Table 1). We report on an 8-year-old girl with CM-I who manifested hypoglycemia associated with headache, vertigo, syncope and hepatic steatosis.

\section{Case Report}

The subject, now aged eight years, was born at 38 weeks of gestation by normal vaginal delivery with Apgar scores of 8 and 10 after one and five minutes, respectively. Her birth weight was $3180 \mathrm{~g}$. The neonatal period was normal. Prenatal karyotype was normal 46,XX and her family history was unremarkable.

At one year of age she presented a first episode of vertigo and syncope from which she recovered. Neurological examination was normal and a diagnosis of benign infantile spasm was made. There was no recurrence in the following two years. At three years of age she presented with a second episode of syncope. During this episode EEG revealed parietooccipital slow waves, while routine analysis discovered hypoglycemia $(52 \mathrm{mg} / \mathrm{dL})$. Due to suspected glycogenosis she underwent liver biopsy that revealed hepatic steatosis. At this time no hepatomegaly was present, liver function tests were normal. Her body length was 98 $\mathrm{cm}$ and weight was $15 \mathrm{~kg}$. For the following four years the patient remained in a stable clinical condition.

At eight years of age the girl was admitted to our Pediatric Department due to new episodes of syncope, headeache, hypoglycemia and for the occurrence of asthenia with monthly uterine hemorrhage. Neurological and endocrinological examination was normal; metabolic analyses including CEA, FP, CA125, hCG, endomysial (EMA) IgG, IgA, antigliadin (AGA) IgG, IgA were also normal. Abdominal and pelvic ultrasound scans were normal except for a low grade of hepatic steatosis. Her body length was $130 \mathrm{~cm}$, weight $30 \mathrm{~kg}$ and abdominal girth was $46.5 \mathrm{~cm}$. A 24-hour EEG showed bilateral slow spikes and waves in parietooccipital regions but predominantly in the right hemisphere. Cerebral magnetic resonance imaging revealed a $15 \mathrm{~mm}$ herniation of the cerebellar tonsils consistent with a diagnosis of CM-I (Figure1).

At this time, the patient underwent suboccipital decompression surgery. This gave good clinical results including complete control of her episodes of syncope and headache. Magnetic resonance imaging revealed that the cerebellar tonsils were now in a normal position. At present, no further episodes of syncope, headeache,
Correspondence: Alberto Spalice, Chair of Paediatrics, Division of Child Neurology, Department of Paediatrics, University "La Sapienza”, Rome, viale Regina Elena 324, 00161 Roma, Italy. E-mail: a.spalice@tiscali.it

Key words: Chiari type I malformation.

Received for publication: 14 January 2010.

Revision received: 18 February 2010.

Accepted for publication: 19 February 2010.

This work is licensed under a Creative Commons Attribution 3.0 License (by-nc 3.0).

CC Copyright L. Tarani et al., 2010

Licensee PAGEPress, Italy

Pediatric Reports 2010; 2:e8

doi:10.4081/pr.2010.e8

or hypoglycemia have been reported and the patient remains in good clinical condition after a 24-month follow-up. Her body length was 140 $\mathrm{cm}$, weight was $40 \mathrm{~kg}$ and abdominal girth was $60.4 \mathrm{~cm}$.

\section{Discussion}

Chiari malformations comprise a pathological continuum of hindbrain maldevelopment characterized by downward herniation of the cerebellar tonsils. ${ }^{7} \mathrm{CM}-\mathrm{I}$ is the most common and the least severe of the spectrum, often diagnosed in adulthood. The hallmark of CM-I is caudal displacement of the peglike cerebellar tonsils below the level of the foramen magnum, a phenomenon variably referred to as congenital tonsillar herniation, tonsillar ectopia, or tonsillar descent. The consequent impaction of the foramen magnum, with compression of the cervicomedullary junction by the ectopic tonsils, and interruption of normal flow of cerebrospinal fluid (CSF) through the region, are thought to produce the clinical syndrome.

Chiari type II malformation is less common and more severe, and is almost invariably associated with spina bifida cystica (myelomeningocele). Because of its greater severity it becomes symptomatic in infancy or early childhood. The hallmark of the condition is caudal displacement of lower brainstem (medulla, pons, and $4^{\text {th }}$ ventricle) through the foramen magnum. Symptoms arise from dysfunction of the brainstem and the lower cranial nerves. Chiari type III and IV malformations are exceedingly rare and are generally incompatible with life and are, therefore, of minor clinical significance. The type III malformation refers to herniation of the cerebellum into a high cervical myelomeningocele, whereas type 


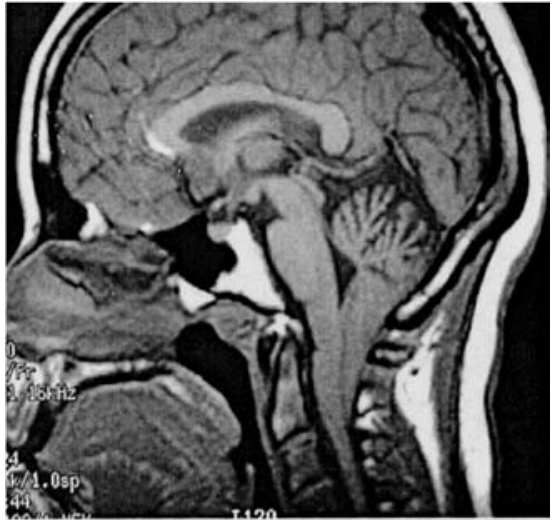

Figure 1. Sagittal view showing $15 \mathrm{~mm}$ herniation of the cerebellar tonsils consistent with diagnosis of Chiari I malformation.

IV refers to cerebellar agenesis. ${ }^{6}$ Importantly, it is not clear whether the 4 types of Chiari malformation represent a disease continuum that corresponds to a single disorder. The 4 types (particularly types III and IV) are increasingly believed to have a distinct pathoetiology and share few common features other than their name ${ }^{8,12-13}$ (Table 2).

With the advent of MRI these malformations are increasingly identified but little is known about their clinical manifestations during childhood. ${ }^{8}$ Some authors have speculated that CM-I is a dynamic disease, a hypothesis based on the observation that the number of symptomatic patients may increase with age. ${ }^{1,4-5}$ However, despite evidence that surgical intervention in CM-I is warranted, there is no consensus on the timing of the intervention nor on the procedure to be performed. The situation is exacerbated by the lack of any reliable information regarding the natural evolution of CM-I and only a few literature reports have addressed these issues.

Symptoms related to CM-I overlap with a variety of other disorders including multiple sclerosis (MS), fibromyalgia (FM), and chronic fatigue syndrome (CFS). Less common differential diagnoses include spinal cord syndromes due to vitamin deficiencies (B12, E), hereditary cerebellar ataxia, and cough syncope. The latter symptom has also been reported in both FM and CFS..$^{12,13}$ Its co-occurrence in CM-I, in addition to other non-specific symptoms, has resulted in FM and CFS patients being offered decompressive surgery even in the absence of any evident hindbrain anomalies. Despite much attention in the press and in medical publications, surgery remains controversial. There have been limited reports of success, ${ }^{14-17}$ but it is generally not advisable to offer decompressive surgical treatment to patients with a relevant clinical picture but in whom the radiographic features of CM-I have not been demonstrated (Table 1).

Table 1. Symptomatology of the Chiari I malformation

\begin{tabular}{|c|c|c|}
\hline Cerebellar & Brainstem & Spinal cord (syrinx) \\
\hline Ataxia, nystagmus & $\begin{array}{l}\text { Hoarse voice, palatal dysfunction, } \\
\text { tongue atrophy, fasciculation }\end{array}$ & $\begin{array}{l}\text { Sensory } \\
\text { Dissociated sensory loss } \\
\text { Dysesthesia }\end{array}$ \\
\hline \multirow[t]{2}{*}{$\begin{array}{l}\text { General } \\
\text { Neck pain, headache }\end{array}$} & Dysphagia, hiccup & \\
\hline & $\begin{array}{l}\text { Severe snoring, respiratory, dysrhythmias, } \\
\text { facial numbness, drop attacks, dysartria, } \\
\text { nystagmus, dysequilibrium, ocular motor } \\
\text { nerve palsies }\end{array}$ & $\begin{array}{l}\text { Motor } \\
\text { Weakness } \\
\text { Muscle wasting } \\
\text { Spasticity } \\
\text { Autonomic system } \\
\text { Horner syndrome } \\
\text { Urinary incontinence } \\
\text { Charcot joints }\end{array}$ \\
\hline
\end{tabular}

Table 2. Age-related position of the cerebellar tonsils.

\begin{tabular}{lc} 
Age & Limit of tonsillar position below foramen maginum \\
First decade & $6 \mathrm{~mm}$ \\
Second to third decades & $5 \mathrm{~mm}$ \\
\hline Fourth to eighth decades & $4 \mathrm{~mm}$ \\
Ninth decade & $3 \mathrm{~mm}$ \\
\hline
\end{tabular}

There is considerable evidence that headache, vertigo and syncope, as in the patient reported here, are typical signs and symptoms of CM-I, and surgical decompression has been the treatment of choice in order to achieve clinical control. ${ }^{14-17}$ However, in our patient, hypoglycemia was an early central feature; indeed this symptom is far from rare in CM-I patients. The cause of hypoglycemia in CM-I is not understood, but we propose that hyperinsulinism is responsible. The brainstems of these patients are anatomically and functionally abnormal, and brainstem compression due to hindbrain herniation leads to dysfunction in the area of the nucleus tractus solitarii, the dorsal motor nucleus (DMX), and the vagus nerve. These areas are likely to be stimulated by changes in local pressure and turgor, by mechanical compression with or without shunt failure, or by $\mathrm{CO}_{2}$ retention. We suggest that direct stimulation of the vagal nuclei stimulates pancreatic islet cells to secrete insulin. This effect is compounded by the inability of the normal homeostatic mechanisms to correct the hypoglycemia because of concurrent brainstem dysfunction. ${ }^{18}$

Our patient also exibited hepatic steatosis. In our opinion, this is probably a chance association and is unlikely to be mechanistically involved in the pathoetiology of her condition.

It is of note that earlier imaging on our patient revealed cerebellar herniation $(5 \mathrm{~mm})$ that was considered normal and it, therefore, seems likely that some cases with CM-I are unrecognized. This may be related to the fact that tonsillar ectopia of $5 \mathrm{~mm}$ has been widely adopted as the cut-off for a diagnosis of CM-I.
However, it is increasingly recognized that subjects with lesser degrees of tonsillar ectopia can also develop classic neurological symptoms and syringomyelia that are amenable to neurosurgical intervention; ${ }^{19-23}$ the definition of CM-I may, therefore, need to be revised. ${ }^{20}$ However, the cerebellar tonsils typically ascend with age and are, therefore, situated lower during early childhood, ${ }^{23}$ raising the possibility that the $5 \mathrm{~mm}$ cutoff may indeed be appropriate in the pediatric population (Table 2).

In conclusion, further studies will be required to refine the definition of type I Chiari malformation and to improve our understanding of the neurological symptoms and natural history of the condition so as to develop evidence-based strategies to determine the appropriateness, timing, and method of neurosurgical intervention.

\section{References}

1. Milhorat TH, Chou MW, Trinidad EM, Kula RW, Mandell M, Wolpert C, Speer MC. Chiari I malformation redefined: clinical and radiographic findings for 364 symptomatic patients. Neurosurgery 1999;44: 1005-17.

2. Sgouros S, Kountouri M, Natarajan K. Posterior fossa volume in children with Chiari malformation Type I. J Neurosurg. 2006;105:S101-S6.

3. Meadows J, Kraut M, Guarnieri M, Haroun RI, Carson BS. Asymptomatic Chiari Type I 
malformations identified on magnetic resonance imaging. J Neurosurg 2000;92:9206.

4. Greenlee JD, Donovan KA, Hasan DM, Menezes AH. Chiari I malformation in the very young child: the spectrum of presentation and experience in 31 children under age 6 years. Pediatrics 2002;110:1212-9.

5. Mueller DM, Orò JJ. Prospective analysis of presenting symptoms among 265 patients with radiographic evidence of Chiari malformation type I with or without syringomyelia. J Am Acad Nurse Pract 2005;16:134-8.

6. Iannetti P, Spalice A, De Felice Ciccoli C, et al. Seizures in paediatric Chiari type I malformation: the role of single-photon emission computed tomography. Acta Paediatr 2002;91:313-7.

7. Tubbs RS, Lyerly MJ, Loukas M, et al. The pediatric Chiari I malformation: a review. Childs Nerv Syst 2007;23:1239-50.

8. Novegno F, Caldarelli M, Massa A, et al. The natural history of the Chiari Type I anomaly. J Neurosurg Pediatr 2008;2:17987.

9. Weinberg JS, Freed DL, Sadock J, et al. Headache and Chiari I malformation in the pediatric population. Pediatric Neurosurg 1998;29:14-8.
10. Taylor FR, Larkins MV. Headache and Chiari I malformation: Clinical presentation, diagnosis, and controversies in management. Curr Pain Headache Rep 2002 6:331-7.

11. Arnett BC. Tonsillar ectopia and head. Neurol Clin 2004;22:229-36.

12. Schijman E. History, anatomic forms, and pathogenesis of Chari I malformations. Childs Nerv System 2004;20:323-8.

13. Steinbok P. Clinical features of Chari I malformations. Childs Nerv System 2004; 20:329-31.

14. Navarro R, Olavarria G, Seshadri R, et al. Surgical results of posterior fossa decompression for patients with Chiari I malformation. Childs Nerv Syst 2004;20:349-56.

15. Navarro R, Alonso I, Costa JM. Relevance of surgical strategies for the management of paediatric Chiari type I malformation. Childs Nerv Syst. 2007 23(7):725-6.

16. Tubbs RS, McGirt MJ, Oakes WJ. Surgical experience in 130 pediatric patients with Chiari I malformation. J Neurosurg 2003; 99:291-6.

17. Bindal AK, Dunsker SB, Tew JM Jr. Chiari I malformation: classification and management. Neurosurgery 1995;37:1069-74.

18. Rekate HL, Nadkarni TD, Teaford PA, Wallace D. Brainstem dysfunction in
Chiari malformation presenting as profound hypoglicemia: presentation of four cases, review of literature, and conjecture as to mechanism. Neurosurgery 1999;45: 386-91.

19. Aboulezz AO, Sartor K, Geyer CA, Gado MH. Position of cerebellar tonsils in the normal population and in patients with Chiari malformation: a quantitative approach with MR imaging. J Comput Assist Tomogr 1985;9:1033-6.

20. Barkovich AJ, Wippold FJ, Sherman JL, Citrin CM. Significance of cerebellar tonsillar position on MR. Am J Neuroradiol 1986;7:795-9.

21. Oldfield EH, Muraszko K, Shawker TH, Patronas NJ. Pathophysiology of syringomielia associated with Chiari I malformation of the cerebellar tonsils. J Neurosurg 1994;80:3-15.

22. Nishizawa S, Yokoyama T, Yokota N, et al. Incidentally identified syringomyelia associated with Chiari I malformations: is early interventional surgery necessary? Neurosurgery 2001;49:637-40.

23 Mikulis DJ, Diaz 0, Egglin TK, Sanchez R. Variance of the position of the cerebellar tonsils with age: preliminary report. Radiology 1992;183:725-8. 